\title{
MODIFIKASI MESIN POMPA AIR SAWAH DENGAN MENGGUNAKAN BAHAN BAKAR BENSIN MENJADI GAS
}

\author{
${ }^{(1)}$ Achmad Rijanto, ${ }^{(2)}$ Suesthi Rahayuningsih \\ (1)Program Studi Teknik Mesin, Universitas Islam Majapahit \\ (2)Program Studi Pendidikan Matematika, Universitas Islam Majapahit \\ Jalan Raya Jabon Km 0,7 Mojokerto \\ Email: rijanto1970@gmail.com
}

\begin{abstract}
Abstrak
Penggunaan bahan bakar dengan biaya yang lebih murah dan ramah lingkungan merupakan kebutuhan masyarakat yang tidak dapat dihindari. Terutama bagi para petani yang menggunakan bahan bakar minyak untuk bahan bakar mesin pompa air sawahnya. Oleh karena itu perlu diambil langkah alternatif substitusi penggunaan bahan bakar yang lebih murah pada penggunaan mesin pompa air sawah, yaitu substitusi dari bahan bakar minyak (BBM) ke bahan bakar gas (BBG). Tujuan penelitian ini adalah memodifikasi mesin pompa air sawah menggunakan bahan bakar minyak minyak (bensin) menjadi berbahan bakar gas LPG (Liquified Petroleum Gas) dan untuk mengetahui konsumsi bahan bakar mesinnya. Metode yang digunakan adalah metode ekperimental dan modifikasi mesin. Hasil penelitian yang diperoleh yaitu berupa satu unit mesin hasil modifikasi mesin pompa air sawah berbahan bakar bensin menjadi gas LPG, dan konsumsi bahan bakar LPG sebesar 0,300 - 0,360 kg/jam, pada putaran mesin $2000 \mathrm{rpm}$.
\end{abstract}

Kata kunci : modifikasi, mesin, pompa

\begin{abstract}
The use of fuel that was cheaper and environmentally friendly was an unavoidable need for the community. Especially for farmers who used fuel oil to fuel their rice field water pumping machines. Therefore it was necessary to take alternative steps to substitute the use of cheaper fuels in the use of irrigation pump machines, namely the substitution of fuel oil (BBM) to gas fuel (BBG). The purpose of this study was to modify the field water pump engine using oil fuel (gasoline) to fuel LPG (Liquified Petroleum Gas) gas and to determine the engine fuel consumption. The method used was experimental method and machine modification. The results obtained were in the form of a machine unit modified from a petrol field Water pump engine to LPG gas, and LPG fuel consumption of 0.300 $0.360 \mathrm{~kg} / \mathrm{hour}$, at $2000 \mathrm{rpm}$ engine speed.
\end{abstract}

Key words : modification, engine, pump

\section{PENDAHULUAN}

Penggunaan bahan bakar yang murah dan ramah lingkungan merupakan keniscayaan yang dibutuhkan oleh setiap masyarakat. Apalagi dengan semakin berkurangnya produksi bahan bakar minyak (BBM), sehingga berdampak pada semakin mahalnya harga BBM tersebut. Disamping Itu BBM merupakan bahan bakar fosil yang termasuk jenis bahan bakar yang tidak dapat diperbarui. Dan jika dipergunakan terus menerus, lama kelamaan akan cepat habis. Oleh karena itu perlu adanya inovasi baru terhadap teknologi 
penggunaan bakar bakar alternatif sebagai konversi dari penggunaan BBM. Teknologi konversi bahan bakar beraneka ragam, salah satunya teknologi konversi penggunaan BBM ke bahan bakar gas (BBG). Pemilihan gas alam sebagai pengkonversi BBM, dikarenakan gas alam di Indonesia mempunyai jumlah produksi yang semakin meningkat, harganya lebih murah dari BBM, dan ramah lingkungan.

Di bidang permesinan, banyak mesin yang masih menggunakan BBM sebagai sumber energinya, salah satunya adalah mesin pompa air sawah untuk penyediaan air di persawahan. Mesin pompa air saawah di pasaran masih banyak menggunakan BBM (bensin atau solar) sebagai sumber energinya. Mesin pompa air sawah ini banyak digunakan oleh para petani untuk mengairi persawahannya. Kenaikan harga BBM menyebabkan biaya operasional produksi dengan menggunakan mesin pompa air ini menjadi semakin besar pula. Hal ini menjadi masalah bagi para petani yang mengairi sawahnya dengan menggunakan mesin ini. Oleh karena itu perlu dicari upaya untuk menekan biaya operasional produksi pertanian, melalui pengurangan biaya penggunaan bahan bakarnya. Upaya tersebut adalah dengan cara menggunakan bahan bakar yang lebih murah dari penggunaan BBM. Berdasarkan perbandingan harga $\mathrm{BBM}$ dan BBG di pasaran, sebagai alternatif pilihan bahan bakar yang digunakan untuk sumber energi pompa air sawah yaitu bahan bahan gas (BBG). Sehubungan masih langkanya mesin pompa air sawah berbahan bakar gas di pasaran, maka perlu dilakukan penelitian tentang mesin pompa air sawah ini.

Pemakaian bahan bakar gas LPG lebih hemat, jika dibandingkan dengan penggunaan BBM sebagai bahan bakar mesin. Pengujian $3 \mathrm{~kg}$ tabung gas LPG dapat menempuh jarak $250 \mathrm{~km}$ dengan harga Rp. 15.000,-. Sedangkan pemakaian bahan bakar premium, satu liter premium dengan harga $\mathrm{Rp}$. 5.000,dapat menempuh jarak $55 \mathrm{~km}$, sehingga untuk menempuh jarak $250 \mathrm{~km}$ memerlukan 4,55 liter dengan harga $\mathrm{Rp}$. 22.750,-. Dengan demikian pemakaian bahan bakar gas LPG dapat menghemat uang sebesar Rp. 7.750,-[1]. Putaran mesin tinggi (3.200) konsumsi BBM premium jauh lebih besar dibandingan BBG LPG yaitu $0,511 \mathrm{~kg} / \mathrm{jam}$ untuk BBM Premium, dan 0,373 kg/jam untuk BBG LPG. Propeller yang dianjurkan bagi para nelayan adalah tipe $4-5$, di mana propeller tipe ini terbukti lebih ekonomis saat menggunakan BBG LPG dengan selisih mencapai Rp. 3.866,selama 4 jam pemakaian mesin ${ }^{[2]}$. Dalam menggunakan bahan bakar gas LPG, lebih menguntungkan atau lebih efisien di bandingkan dengan menggunakan bahan bakar minyak tanah dalam memproduksi kue bagea ${ }^{[3]}$. Dilihat dari komposisi emisi gas buang yang dihasilkan BBG (LPG) lebih ramah lingkungan dibandingkan dengan BBM (bensin). Perbandingan emisi gas buang bensin dan $\mathrm{LPG}^{[4]}$, dapat dilihat pada tabel 1.

Tabel 1. Tabel emisi gas buang bensin dan LPG

\begin{tabular}{llll}
\hline No & Emisi & Bensin & LPG \\
\hline 1 & $\mathrm{CO}(\mathrm{gr} / \mathrm{km})$ & 0,87 & 0,72 \\
\hline 2 & $\mathrm{HC}(\mathrm{gr} / \mathrm{km})$ & 0,14 & 0,12 \\
\hline 3 & $\mathrm{NOX}(\mathrm{gr} / \mathrm{km})$ & 0,16 & 0,13 \\
\hline
\end{tabular}

Tujuan penelitian ini adalah memodifikasi mesin pompa air sawah berbahan bakar minyak menjadi berbahan bakar gas LPG, dan untuk mengetahui konsumsi bahan bakarnya. Dengan adanya mesin pompa air berbahan bakar gas LPG ini, diharapkan kepada masyarakat pengguna mesin ini, khususnya para petani dapat beralih dari pengguna BBM menjadi pengguna BBG, karena BBG lebih murah, ramah lingkungan dan ketersediaanya lebih banyak di Indonesia. 


\section{METODE PENELITIAN}

Metode penelitian yang digunakan dalam penelitian ini adalah modifikasi dan eksperimental. Modifikasi digunakan untuk mengubah mesin pompa air sawah dengan menggunakan bahan bakar bensin menjadi berbahan bakar gas LPG. Proses modifikasi ini dengan mengubah komponen pencampur bahan bakar bensin dan udara (karburator standar), menjadi campuran gas LPG dan udara (karburator konverter). Sedangkan eksperimental dilakukan untuk menguji konsumsi bahan bakar gas LPG yang digunakan oleh mesin pompa air sawah selama pemakaian mesin.

Bahan yang digunakan dalam penelitian ini meliputi mesin pompa air sawah standar berbahan bakar bensin, konverter kit, selang masuk dan keluar air, gas LPG dalam tabung, regulator gas LPG high pressure, selang gas LPG high pressure, karet ban, valve/kran puyer gas LPG, oli mesin, packing karburator, klem selang LPG, klem selang kawat dan bak penampungan air.

Pompa air sawah berbahan bakar bensin adalah mesin yang akan dimodifikasi menjadi bahan bakar gas dengan spesifikasi; diameter lubang hisap dan buang berukuran $80 \mathrm{~mm}$ (3"), tinggi total $32 \mathrm{~m}$, tinggi hisap $8 \mathrm{~m}$, kapasitas aliran maksimum 1000 liter/menit, engine model GX 160, tipe OHV, isi silinder $163 \mathrm{cc}$, tenaga keluaran maksimal (bersih) 3,6 kW (4,8 HP)/ $3600 \mathrm{rpm}$, tenaga keluaran maksimal (kotor) 4,1 kW (5,5 HP)/ $3600 \mathrm{rpm}$, kapasitas oli mesin 0,6 liter, kapasitas bahan bakar 3,8 liter dan dimensi PxLxT $550 \mathrm{~mm}$ x $390 \mathrm{~mm}$ x $450 \mathrm{~mm}$. Konverter kit, merupakan komponen yang digunakan untuk mengubah pembakaran dengan menggunakan bensin menjadi pembakaran yang menggunakan gas LPG. Selang masuk (suction) dan selang keluar (discharge) air, berupa selang berbentuk spiral yang terbuat dari plastik digunakan pada pipa masuk dan pipa keluar pada mesin. Gas LPG dalam tabung ukuran $3 \mathrm{~kg}$, digunakan sebagai bahan bakar mesin modifikasi. Regulator gas LPG high pressure, digunakan untuk mengatur pemakaian gas LPG, yang dihubungkan langsung dengan katup tabung LPG. Selang gas LPG high pressure, digunakan untuk media aliran gas LPG ke konverter kit pada mesin. Karet ban, digunakan untuk pengikat pada selang pipa masuk dan keluar, agar tidak terjadi kebocoran. Valve/kran puyer gas LPG digunakan untuk mengatur gas yang menuju konverter kit. Oli mesin digunakan sebagai pelumas mesin. Packing karburator dipasang saat mengganti karburator bensin dengan karburator LPG, agar tidak terjadi kebocoran. Klem selang LPG, digunakan untuk mengikat sambungan selang dengan regulator dan konverter kit. Klem selang kawat, digunakan untuk mengikat selang air masuk dan keluar, agar terikat lebih kuat. Bak penampungan air, digunakan untuk menampung air yang dihisap dan dilepas.

Alat yang dipakai sebagai alat ukur untuk pengujian pada penelitian eksperimental ini, terdiri dari timbangan digital, tachometer digital dan jam digital (stopwatch).

Timbangan digital, digunakan sebagai alat untuk mengukur massa gas dan tabung LPG. Alat ukur yang digunakan merk Prohex. Alat ini dilengkapi dengan high precision strain gauge sensor, division 0,1-1 g, layar 0,6", aotomatic zero resetting, low power indicator, tare, two model unit (operation manual sheet). Kapasitas maksimal sebesar $40 \mathrm{~kg}$, dengan tingkat ketelitian 1 gram. Tachometer digital berfungsi sebagai alat untuk mengukur kecepatan putaran mesin pompa air sawah. Tachometer yang digunakan untuk penelitian merk Digilife, model DT $2234 C^{+}$. Alat ini dapat mengukur putaran mesin mulai dari 2,5 rpm sampai $99.999 \mathrm{rpm}$. Spesifikasi yang lain alat 
ini; layar 5 digits, $18 \mathrm{~mm}$, tingkat akurasi $\pm 0,05 \%+1$ digit, resolution $0,1 \mathrm{rpm}$ (2,5-999,9), $1 \mathrm{rpm}$ (diatas $1000 \mathrm{rpm}$ ), sampling time 0,8 detik di atas $60 \mathrm{rpm}$, test range select automatic dan cicuit exclusif one-chip of microcomputer LSI circuit. Stopwatch dipakai untuk mengukur lamanya waktu konsumsi bahan bakar gas LPG. Alat ini mempunyai tingkat ketelitian 0,01 detik.

Langkah-langkah penelitian yang dilakukan sesuai dengan diagram alur penelitian yang ditunjukkan pada gambar 1. Langkah pertama yang dilakukan yaitu menyiapkan bahan dan peralatan penelitian. Setelah bahan dan peralatan penelitian siap, lalu memodifikasi mesin pompa air sawah berbahan bakar bensin menjadi bahan bakar gas LPG dengan cara mengganti karburator bensin menjadi karburator gas LPG (konverter kit). Sebelum memasang konverter kit terlebih dahulu memasang packing, agar tidak terjadi kebocoran gas. Selanjutnya memasang selang pipa masuk dan keluar, agar lebih kuat dan tidak terjadi kebocoran, diikat dengan klem kawat dan karet ban. Setelah itu dipasang berturut-turut selang high pressure, regulator high pressure, tabung gas dan valvel kran puyer. Kesemuanya dirangkai menjadi satu, sehingga menjadi mesin modifikasi pompa air sawah berbahan bakar gas LPG. Setelah mesin selesai dirangkai, kemudian dilakukan uji konsumsi bahan bakar LPG, sebelum dilakukan pengujian pompa air dinyalakan, Setelah menyala, proses uji segera dilakukan. Terlebih dulu tabung gas ditimbang dengan menggunakan timbangan digital dan hasilnya dicatat sebagai massa awal. Setelah itu mesin dinyalakan pada putaran sebesar $2000 \mathrm{rpm}$, diukur dengan menggunakan tachometer digital. Kemudian diatur waktu pemakaian bahan bakar gas LPG atau penyalaan mesin selama 300 detik dengan menggunakan stopwatch. Setelah itu dibaca massa tabung gas setiap 300 detik, massa ini sebagai massa akhir. Eksperimen ini dilakukan berulangulang, sampai menemukan data yang valid. Konsumsi bahan bakar LPG diperoleh dari selisih massa awal terhadap massa akhir tabung gas LPG.

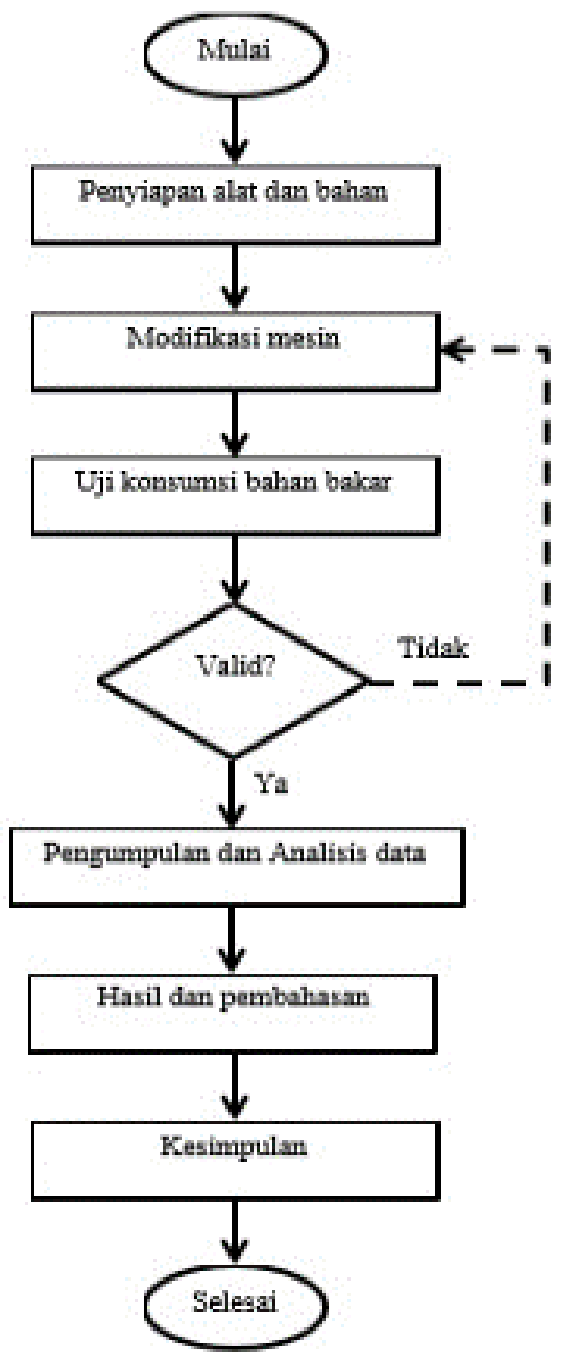

Gambar 1. Diagram alur penelitian

Data hasil eksperimen yang telah valid, dikumpulkan dan dianalisis lebih lanjut, sedangkan jika data yang diperoleh tidak valid, maka dilakukan pengecekan modifikasi mesin dan uji ulang. Setelah data valid dan dianalisis, maka dilakukan pembahasan hasil penelitian, dan yang terakhir diambil kesimpulan dari penelitian ini. 


\section{HASIL DAN PEMBAHASAN}

Modifikasi mesin pompa air sawah dari berbahan bakar bensin menjadi berbahan bakar gas LPG telah dilakukan. Modifikasi ini dilakukan dengan menganti komponen karburator bensin dengan karburator gas LPG sebagai konverternya. Karburator ini sebagai komponen yang mencampurkan udara dengan bahan bakar pada motor pembakaran dalam. Motor bakar dipakai sebagai motor penggerak. Motor bakar dikenal juga dengan nama mesin pembakaran dalam (internal combustion engine) adalah suatu alat atau komponen mesin yang prinsip kerjanya mengubah energi kimia menjadi energi kalor, lalu diubah lagi menjadi energi mekanik atau gerak. Proses pembakaran terjadi di dalam motor bakar, sehingga gas pembakaran yang terjadi berfungsi sekaligus sebagai fluida kerja ${ }^{[5]}$.

Konverter kit merupakan alat yang digunakan untuk mengkonversi BBG, agar dapat digunakan untuk mesin yang berbahan bakar minyak (BBM. Pada kendaraan bermotor diperlukan peralatan tambahan, agar dapat memakai BBG sebagai bahan bakar, peralatan tersebut dinamakan konverter kit. Alat ini berfungsi untuk menyesuaikan kerja mesin, sehingga pemakaian BBG dapat diterapkan pada mesin berbahan bakar minyak. Secara umum terdapat dua teknik dalam pemakaian gas sebagai BBG, yaitu: gas dihisap (sistem vacum) dengan enggunakan efek vacum pada ruang bakar dan gas diinjeksikan ke dalam ruang bakar (sistem injeksi) ${ }^{[6]}$. Konverter kit dengan teknik dihisap dengan memakai teknik vakum dapat diterapkan pada motor penggerak mesin parut kelapa yang menggunakan bahan bakar gas ${ }^{[7]}$. Konverter kit dapat dlihat pada gambar 2 berikut.

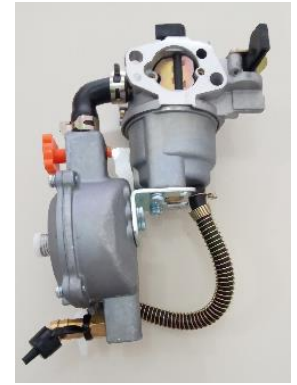

Gambar 2. Konverter kit gas LPG

Setelah dilakukan penggantian komponen pencampur bahan bakar dan udara, dengan konverter kit gas LPG dan dilakukan perakitan semua komponen pendukungnya, antara lain tabung gas, selang pipa hisap dan keluar, selang gas LPG beserta regulatornya, maka modifikasi mesin pompa air sawah siap untuk diuji. Mesin pompa air sawah yang telah dimodifikasi dari bahan bakar bensin menjadi bahan bakar gas LPG dapat dilihat pada gambar 3 .

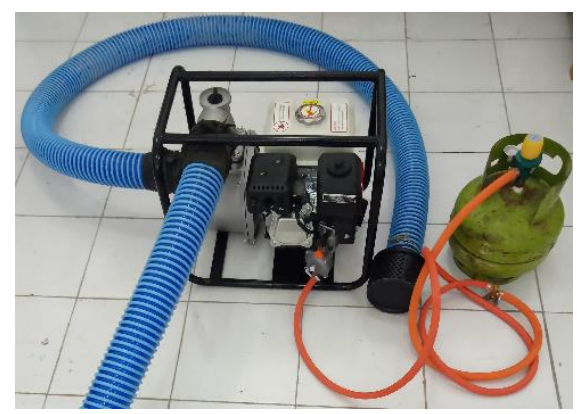

Gambar 3. Mesin pompa air sawah hasil modifikasi

Karakteristik bensin dengan gas LPG mempunyai kemiripan. Bensin adalah zat cair yang diperoleh dari hasil pemurnian minyak bumi. Bensin dapat dipakai sebagai bahan bakar motor bensin. Sebagai bahan bakar, bensin mempunyai komposisi elemen-elemen, yaitu Carbon, Hidrogen, Nitrogen, Sulphur, Oksigen dan elemen lain seperti abu (ash) dan air (moisture). LPG (liquified petroleum gas) adalah suatu campuran dari unsur-unsur hidrokarbon yang berasal dari gas alam. Dengan menaikkan tekanan, dan menurunkan suhunya, gas berubah menjadi cair. 
Komponen LPG didominasi propana (C3H8) dan butana (C4H10).

Perbandingan sifat-sifat atau karakteristik bahan bakar gas LPG dengan premium pada tabel 2 .

Tabel 2. Perbandingan karakteristik premium dengan gas LPG

\begin{tabular}{|c|l|c|c|}
\hline No & \multicolumn{1}{|c|}{ Karekteristik } & Premium & LPG \\
\hline 1 & Komposisi & $\mathrm{C}_{8} \mathrm{H}_{18}$ & $\mathrm{C}_{3} \mathrm{H}_{8}$ \\
\hline 2 & Densitas & $752 \mathrm{~kg} / \mathrm{m}^{3}$ & $1,5 \mathrm{~kg} / \mathrm{m}^{3}$ \\
\hline 3 & Berat molekul & $114,8 \mathrm{~kg} / \mathrm{kmol}$ & $44,09 \mathrm{~kg} / \mathrm{kmol}$ \\
\hline 4 & Nilai kalori & $45950 \mathrm{kj} / \mathrm{kmol}$ & $46360 \mathrm{kj} / \mathrm{kmol}$ \\
\hline 5 & AFR stoikiometri & 14,57 & 15,6 \\
\hline 6 & Temperatur penyalaan min. & $360^{\circ} \mathrm{C}$ & $460^{\circ} \mathrm{C}$ \\
\hline 7 & Kecepatan nyala & $20-40 \mathrm{~m} / \mathrm{s}$ & $0,82 \mathrm{~m} / \mathrm{s}$ \\
\hline 8 & Angka oktan & 88 & 110 \\
\hline
\end{tabular}

Pengujian mesin pompa air sawah berbahan bakar gas LPG dilakukan untuk mengetahui konsumsi bahan bakar gas LPG. Konsumsi bahan bakar adalah ukuran bahan bakar yang dikonsumsi motor untuk menghasilkan tenaga mekanis, laju penggunaan bahan bakar tiap detiknya ${ }^{[8]}$. Konsumsi bahan bakar dihitung dengan persamaan 1 sebagai berikut.

$$
\dot{M}_{f}=\frac{M_{b}}{\Delta t}
$$

Keterangan:

$\dot{M}_{f}=$ konsumsi bahan bakar $(\mathrm{gr} /$ detik atau kg/jam)

$M_{b}=$ massa bahan bakar (gr atau kg)

$t=$ waktu penyalaan (detik atau jam)

Untuk melakukan pengujian diperlukan beberapa alat ukur, yaitu tachometer digital, timbangan digital dan pengatur waktu (stopwatch). Pengujian dilakukan pada putaran mesin 2000 rpm selama 300 detik. Massa awal dan akhir diukur dengan timbangan digital. Dari hasil pengujian konsumsi bahan bakar gas LPG yang telah dilakukan diperoleh data sebagaimana ditunjukkan pada tabel 3 .
Tabel 3. Data hasil pengujian konsumsi bahan bakar gas LPG.

\begin{tabular}{cccccc}
\hline $\begin{array}{c}\mathrm{P} \\
\mathrm{ke}\end{array}$ & $\begin{array}{c}n \\
(\mathrm{rpm})\end{array}$ & $\begin{array}{c}M_{0} \\
(\mathrm{gr})\end{array}$ & $\begin{array}{c}M_{I} \\
(\mathrm{gr})\end{array}$ & $\begin{array}{c}M_{b} \\
(\mathrm{gr})\end{array}$ & $\begin{array}{c}t \\
\text { (detik) }\end{array}$ \\
\hline 1 & 2000 & 7155 & 7125 & 30 & 300 \\
\hline 2 & 2000 & 7125 & 7100 & 25 & 300 \\
\hline 3 & 2000 & 7100 & 7070 & 30 & 300 \\
\hline 4 & 2000 & 7070 & 7045 & 25 & 300 \\
\hline 5 & 2000 & 7045 & 7020 & 25 & 300 \\
\hline
\end{tabular}

Keterangan:

$n=$ putaran mesin (rpm)

$M_{0}=$ massa awal (gr atau $\left.\mathrm{kg}\right)$

$M_{1}=$ massa akhir (gr atau $\mathrm{kg}$ )

$M_{b}=$ selisih massa awal dan akhir

$M_{b}=$ massa bahan bakar (gr atau kg)

$t=$ waktu penyalaan (detik atau jam)

Dari data pada tabel 3, dilakukan pengolahan data, dengan cara penghitungan konversi satuan massa dan waktu dari data yang diperoleh selama eksperimen. Hasil pengolahan data ditunjukkan pada tabel 4 .

Tabel 4. Hasil pengolahan data konsumsi bahan bakar gas LPG

\begin{tabular}{ccccccc}
\hline $\begin{array}{c}\mathrm{P} \\
\mathrm{ke}\end{array}$ & $\begin{array}{c}n \\
(\mathrm{rpm})\end{array}$ & $\begin{array}{c}M_{0} \\
(\mathrm{~kg})\end{array}$ & $\begin{array}{c}M_{I} \\
(\mathrm{~kg})\end{array}$ & $\begin{array}{c}M_{b} \\
(\mathrm{~kg})\end{array}$ & $t$ (jam) & $\begin{array}{c}\dot{M}_{f} \\
(\mathrm{~kg} / \mathrm{jam})\end{array}$ \\
\hline 1 & 2000 & 7,155 & 7,125 & 0,0300 & 0,0833 & 0,360 \\
\hline 2 & 2000 & 7,125 & 7,100 & 0,0250 & 0,0833 & 0,300 \\
\hline 3 & 2000 & 7,100 & 7,070 & 0,0300 & 0,0833 & 0,360 \\
\hline 4 & 2000 & 7,070 & 7,045 & 0,0250 & 0,0833 & 0,300 \\
\hline 5 & 2000 & 7,045 & 7,020 & 0,0250 & 0,0833 & 0,300 \\
\hline
\end{tabular}

Berdasarkan pengolahan data pada tabel 4 menunjukkan, bahwa konsumsi bahan bakar gas LPG pada percobaan 1 dan 3 diperoleh nilai yang sama yaitu sebesar 0,360 kg/jam. Sedangkan pada percobaan 2, 4 dan 5 diperoleh nilai konsumsi bahan bakar gas LPG sebesar $0,300 \mathrm{~kg} / \mathrm{jam}$. Dari data tersebut menunjukkan bahwa uji konsumsi bahan bakar gas LPG pada putaran mesin 2000 rpm pada mesin pompa air sawah berbahan bakar gas LPG sebesar 0,300 $\mathrm{kg} / \mathrm{jam}-0,360 \mathrm{~kg} / \mathrm{jam}$. 


\section{KESIMPULAN}

Berdasarkan dari hasil penelitian dan pembahasan yang telah dilakukan, dapat diambil kesimpulan, bahwa penelitian yang telah dilakukan menghasilkan satu unit modifikasi mesin pompa air sawah dari berbahan bakar bensin menjadi berbahan bakar gas LPG, dengan mengganti karburator bahan bakar bensin dengan karburator berbahan bakar gas LPG. Dan dari hasil pengujian konsumsi bahan bakar gas LPG yang telah dilakukan pada putaran mesin $2000 \mathrm{rpm}$, diperoleh konsumsi bahan bakar gas LPG sebesar $0,300 \mathrm{~kg} /$ jam - 0,360 kg/ jam.

\section{UCAPAN TERIMA KASIH}

Disampaikan ucapan terima kasih kepada Direktorat Riset dan Pengabdian Masyarakat (DRPM), Kemenristek/ BRIN yang telah membiayai penelitian ini pada tahun anggaran 2020, dengan kontrak penelitian tahun tunggal nomor 02/LP4MP/UNIM/K/IV/2020, sehingga penelitian ini dapat berjalan dengan baik.

\section{REFERENSI}

[1] Aziz, M. (2013). Analisis Penggunaan Bahan Bakar Liquified Petroleum Gas (LPG) Terhadap Konsumsi Bahan Bakar Dan Emisi Gas Buang Co Dan Hc Pada Motor Supra X 125R Tahun 2009. Nosel, 1(3), 1-10.

[2] Nono, F. G. B., Yudo, H., \& Budiarto, U. (2017). Studi Perbandingan Mesin Outboard Honda GX200 Bahan Bakar Bensin Premium dan Bahan Bakar Elpiji yang Dimodifikasi dengan Konverter Gas pada Kapal Nelayan Tradisional Tanjung Mas. Teknik Perkapalan, 5 (1), 223-236.

[3] Maskur, K., Nursan, N., \& Patra, I. K. (2016). Analisis Dampak
Konversi Minyak Tanah Ke Gas Elpiji Terhadap Peningkatan Pendapatan Industri Bagea Di Kota Palopo. Equilibrium, 2 (1), 123129.

[4] Singh, H, Kumar, C, Yadaf, KD, Yadav, KA, Nishad A, Verma, KA \& Pandey, KA. 2015. Conversion Of Petrol Bike Into Lpg And Emission Check. International Journal Of Mechanical Engineering And Technology (IJMET, ) 6 (4), 6571.

[5] Ramelan, Utomo. (2015). Peningkatan Efisiensi Bahan Bakar Dengan Metode Cyclon Melalui Pemasangan Swirling Vane Pada Sepeda Motor. AUTINDO Politeknik Indonusa Surakarta, 1 (2), 42-47.

[6] Mahmud, R., \& Sungkono, D. (2015). Komparasi penggunaan bahan Bakar Premium Dengan bahan Bakar LPG Sistem Manifold Injeksi Terhadap Kadar Emisi Gas Buang Sepeda Motor 4 Langkah. Integrasi, 7 (1), 45-49.

[7] Rijanto, A., \& Efendi, I. B. (2018). Rancang Bangun Mesin Parut Kelapa dengan Menggunakan Bahan Bakar Gas. Warta Industri Hasil Pertanian, 35(2), 60-67.

[8] Ariawan, BWI, Kusuma, WBGI \& Adnyana, BWI. (2016). Pengaruh Penggunaan Bahan Bakar Pertalite Terhadap Unjuk Kerja Daya, Torsi Dan Onsumsi Bahan Bakar Pada Sepeda Motor Bertransmisi Otomatis. METTEK, 2 (1), 51-58. 